OPEN ACCESS

Edited by:

Guillermo Tellez,

University of Arkansas, United States

Reviewed by:

Roberto Senas Cuesta, University of Arkansas, United States Roman Arteaga,

Highland Animal Hospital, United States

*Correspondence: Tomomi Takano takanot@vmas.kitasato-u.ac.jp

Specialty section: This article was submitted to Veterinary Infectious Diseases,

a section of the journal Frontiers in Veterinary Science

Received: 29 December 2020 Accepted: 20 January 2021

Published: 10 February 2021

Citation:

Takano T, Satoh K and Doki T (2021) Possible Antiviral Activity of 5-Aminolevulinic Acid in Feline Infectious Peritonitis Virus (Feline Coronavirus) Infection.

Front. Vet. Sci. 8:647189. doi: 10.3389/fvets.2021.647189

\section{Possible Antiviral Activity of 5-Aminolevulinic Acid in Feline Infectious Peritonitis Virus (Feline Coronavirus) Infection}

\author{
Tomomi Takano*, Kumi Satoh and Tomoyoshi Doki \\ Laboratory of Veterinary Infectious Disease, Department of Veterinary Medicine, Kitasato University, Towada, Japan
}

Feline infectious peritonitis (FIP) is a life-threatening infectious disease of cats caused by virulent feline coronavirus (FIP virus: FIPV). For the treatment of FIP, several effective antivirals were recently reported, but many of these are not available for practical use. 5-amino levulinic acid (5-ALA) is a low-molecular-weight amino acid synthesized in plant and animal cells. 5-ALA can be synthesized in a large amount, and it is widely applied in the medical and agricultural fields. We hypothesized that 5-ALA inhibits FIPV infection. Therefore, we evaluated its antiviral activity against FIPV in felis catus whole fetus- 4 cells and feline primary macrophages. FIPV infection was significantly inhibited by $250 \mu \mathrm{M}$ 5-ALA. Our study suggested that 5-ALA is applicable for the treatment and prevention of FIPV infection.

Keywords: FIP, coronavirus, 5-aminolevulinic acid, antiviral drug, cat

\section{INTRODUCTION}

Feline infectious peritonitis (FIP) is a life-threatening infectious disease caused by feline coronavirus (FCoV) in domestic and wild Felidae species. FCoV is highly prevalent worldwide in cats. FCoV is an enveloped, single strand positive-sense RNA virus. This virus belongs to the genus Alphacoronavirus in the subfamily Orthocoronavirinae of the family Coronaviridae (1). FCoV is divided into two serotypes based on the amino acid sequence of the spike (S) protein, serotype I FCoV, and serotype II FCoV (2). Serological and genetic surveys revealed that type I FCoV is dominant worldwide (3-5). FCoV is mainly spread by fecal-oral transmission (6). Most FCoV-infected cats are subclinical. However, several mutations occurred in the S protein, leading to development of the virulent type called feline infectious peritonitis virus (FIPV) $(7,8)$. The hallmark pathological findings of FIP in cats are serous fluid in peritoneal and pleural cavities, and pyogranulomatous lesions in several organs (9).

FIP is an immune-mediated and difficult-to-treat virus infection. Several effective antivirals for FIP treatment were recently reported $(10,11)$, but many are not available for practical use. Some anti-FCoV drugs, such as itraconazole, are available at animal hospitals, but their treatment effects are limited (12). As FIP is a chronic and systemic disease, it is difficult to achieve clinical remission. Accordingly, it is desirable that therapeutic drugs for FIP have the following characteristics: (1) Few side-effects for cats, (2) low price, and (3) low mutagenesis of pathogens.

5-amino levulinic acid (5-ALA) is a low-molecular-weight amino acid synthesized in plant and animal cells $(13,14)$. It is an intermediate in biosynthesis of tetrapyrrole. As 5-ALA is highly water-soluble and low cytotoxic, it is widely applied in the medical and agricultural fields (15). 
Several studies on the effects of 5-ALA on infectious disease have been reported. Suzuki et al. reported that when 5-ALA and ferrous ion were orally administered to rodent malaria parasite (Plasmodium yoelii)-infected mice, the mice survived (16). On the other hand, its effects on viral infection are unclear.

In veterinary medicine, photodynamic therapy (PDT) using 5-ALA has been investigated for tumor treatment in dogs (17), but to our knowledge, the effects of 5-ALA on infectious diseases in animals have not been investigated. We investigated whether 5-ALA can be applied as an anti-FCoV drug in vitro.

\section{MATERIALS AND METHODS}

\section{Cell Cultures, Animals, and Viruses}

Felis catus whole fetus (fcwf)-4 cells (kindly supplied by Dr. M. C. Horzinek of Universiteit Utrecht) were grown in Eagles' MEM containing 50\% Leibovitz's L-15 medium, $5 \%$ fetal calf serum (FCS), $100 \mathrm{U} / \mathrm{ml}$ of penicillin, and 100 $\mu \mathrm{g} / \mathrm{ml}$ of streptomycin. The maintenance medium was the same composition as the growth medium except for the concentration of FCS (2\%). For primary macrophages, feline primary macrophages were selected. Feline alveolar macrophages were obtained from four specific-pathogen-free (SPF) cats aged 3-5 years by bronchoalveolar lavage with Hank's balanced salt solution. Feline primary macrophages were maintained in DMEM supplemented with $10 \%$ FCS, $100 \mathrm{U} / \mathrm{mL}$ of penicillin, and $100 \mu \mathrm{g} / \mathrm{mL}$ of streptomycin. SPF cats were maintained in a temperature-controlled isolated facility. The experiment using animals was approved by the President of Kitasato University through judgment of the Institutional Animal Care and Use Committee of Kitasato University (18-050) and performed in accordance with the Guidelines for Animal Experiments of Kitasato University. Sample sizes were determined based on our previous study and the minimum number of cats was used. The

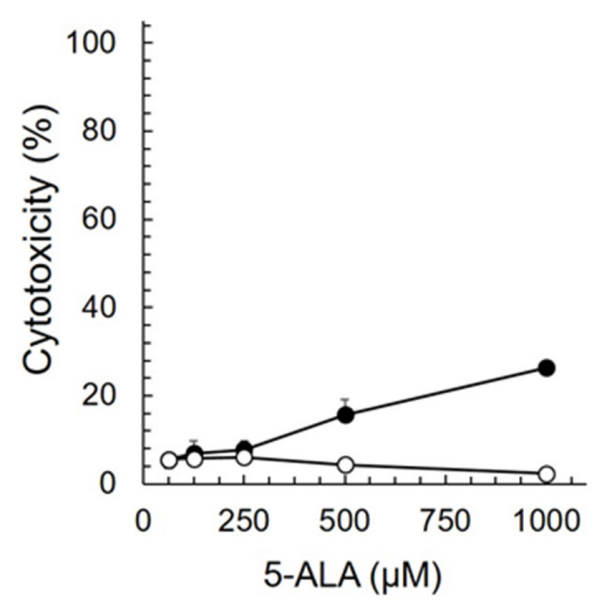

FIGURE 1 | Cytotoxic effects of 5-ALA in fcwf-4 cells. Fcwf-4 cell viability was measured by WST-8 assay. Black circle: 5-ALA. White circle: Vehicle (SFC). The vehicle (solvent control) was the same as that in 5-ALA solution at each serial dilution. The results are shown as the mean \pm SE. Data represent three independent experiments $(n=3)$. type I FCoV KU-2 strain (FIPV-I KU-2) was isolated in our laboratory. FCoV-II 79-1146 was kindly provided by Dr. M. C. Horzinek of Utrecht University. These viruses were grown in fcwf -4 cells at $37^{\circ} \mathrm{C}$.

\section{Compounds}

5-ALA and sodium ferrous citrate (SFC) were obtained from Neopharma Japan (Tokyo, Japan). 5-ALA and SFC were dissolved in maintenance medium at 200 and $50 \mathrm{mM}$, respectively. SFC solution was used as a solvent of 5 ALA. On the day of the experiments, these compounds were diluted to the desired concentrations in maintenance medium.

\section{Cytotoxic Effects of Compounds}

The fcwf- 4 cells were seeded on 96-well plates. The compounds were added in triplicate to the wells. After incubation for $96 \mathrm{~h}$, the culture supernatants were removed, WST-8 solution (Kishida Chemical, Osaka, Japan) was added, and the cells were returned to the incubator for $1 \mathrm{~h}$. The absorbance of formazan produced was measured at $450 \mathrm{~nm}$ using a 96-well spectrophotometric plate reader, as described by the manufacturer. Percentage cell viability was calculated using the following formula: Cell viability $(\%)=[(\mathrm{OD}$ of compound-untreated cells - compound-treated cells)/ (OD of compound-untreated cells)] $\times 100$. The $50 \%$ cytotoxicity concentration $\left(\mathrm{CC}_{50}\right)$ was defined as the cytotoxic concentration of each compound that reduced the absorbance of treated cells to $50 \%$ when compared with that of the untreated cells.

\section{Antiviral Effects of 5-ALA}

Confluent fcwf- 4 cell monolayers were cultured in medium with or without compounds at the indicated concentrations in 24well multi-plates at $37^{\circ} \mathrm{C}$ for 24 or $48 \mathrm{~h}$. Cells were washed and the virus (MOI 0.01) was adsorbed into the cells at $37^{\circ} \mathrm{C}$ for $1 \mathrm{~h}$. After washing, cells were cultured in $1.5 \%$ carboxymethyl cellulose (CMC)-MEM or MEM with or without compounds. In the case of cells cultured in CMC-MEM, the cell monolayers were incubated at $37^{\circ} \mathrm{C}$ for $48 \mathrm{~h}$, fixed, and stained with $1 \%$ crystal violet solution containing $10 \%$ buffered formalin, and the resulting plaques were then counted. The percentage of the decrease or increase in plaques was calculated using the following formula: Percentage of the plaque reduction (\%) = [(plaque number of compound-treated cells) / (plaque number of compound-untreated cells) $] \times 100$. The $\mathrm{EC}_{50}$ was defined as the effective concentration of compounds that reduced the virus titer in the culture supernatant of infected cells to $50 \%$ when compared with that of the virus control. In the case of cells cultured in MEM, the culture supernatants were collected $48 \mathrm{~h}$ post-infection and virus titers were measured by the $\mathrm{TCID}_{50}$ assay.

Primary feline macrophages were cultured in medium with or without compounds at the indicated concentrations in 24well multi-plates at $37^{\circ} \mathrm{C}$ for $48 \mathrm{~h}$. After washing with PBS, FIPV $79-1146\left(1 \times 10^{4}\right.$ TCID $\left._{50}\right)$ was allowed to adsorb to the cells at $37^{\circ} \mathrm{C}$ with $5 \% \mathrm{CO}_{2}$ for $1 \mathrm{~h}$. After washing with PBS, the cells were cultured in the medium and the supernatants were collected. The virus titers were measured by the $\mathrm{TCID}_{50}$ assay. 

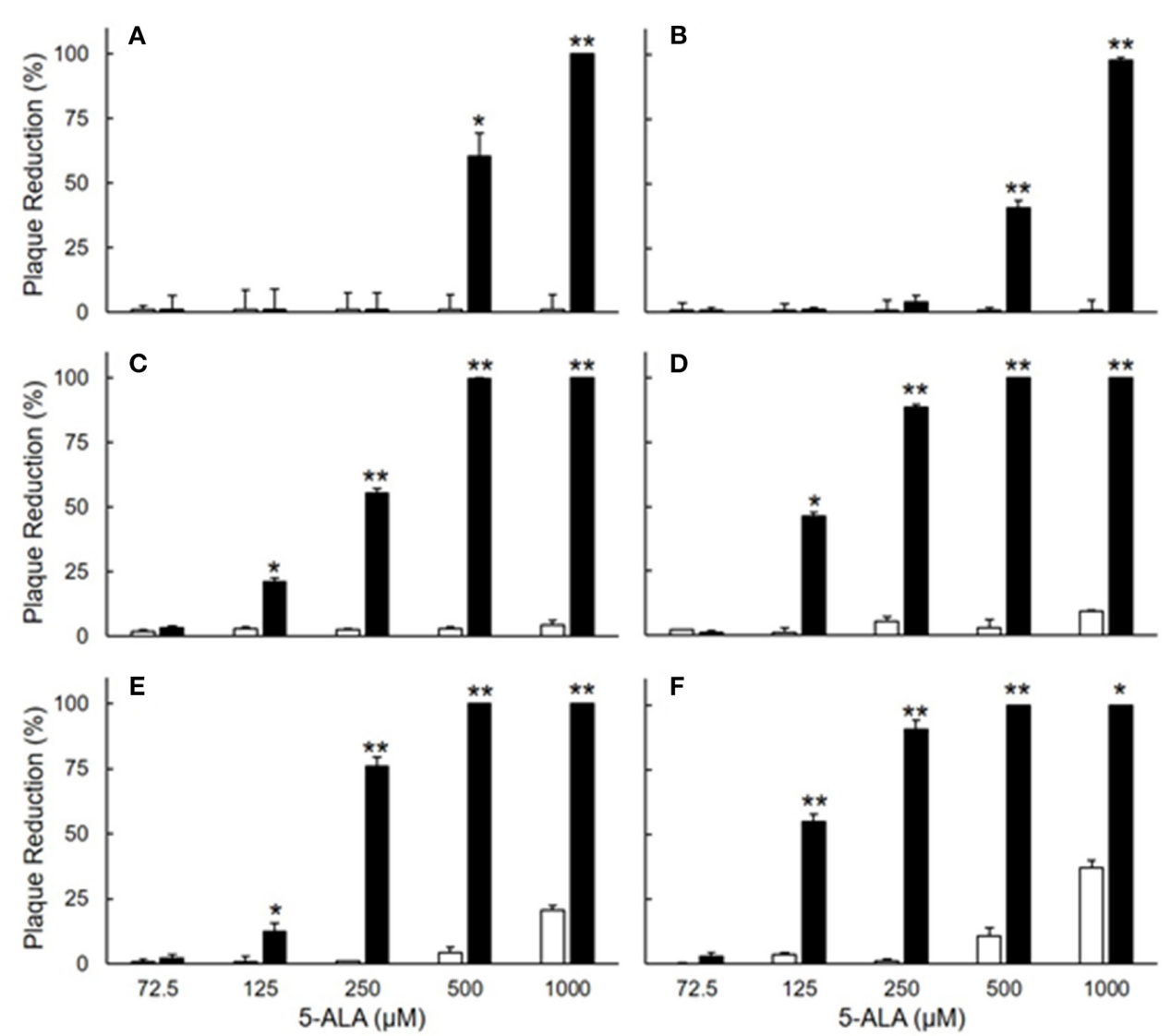

FIGURE 2 | Plaque inhibition assay of FIPV in fcwf-4 cells treated with 5-ALA. (A,B) Effects of 24-h pre-treatment on antiviral activity of 5-ALA. The rate of plaque inhibition of FIPV-infected fcwf-4 cells pre-treated with 5-ALA for $24 \mathrm{~h}$. (C,D) Effects of 24-h pre-treatment and 48-h post-treatment on antiviral activity of 5-ALA. The rate of plaque inhibition of FIPV-infected fcwf-4 cells pre-treated for $24 \mathrm{~h}$ and post-treated for $48 \mathrm{~h}$ with 5-ALA. (E,F) Effects of 48 -h pre-treatment and $48-\mathrm{h}$ post-treatment on antiviral activity of 5-ALA. The rate of plaque inhibition of FIPV-infected fcwf-4 cells pre-treated for $48 \mathrm{~h}$ and post-treated for $48 \mathrm{~h}$ with 5 -ALA. (A,C,E) type I FIPV. (B,D,F) type II FIPV. Black bar: 5-ALA. White bar: Vehicle (solvent control). The results are shown as the mean \pm SE. Data represent four independent experiments $(n=4) .{ }^{* *} p<0.01\left({ }^{*} p<0.05\right)$ vs. vehicle.

\section{Statistical Analysis}

Data from only two groups were analyzed using the Student's $t$ test (Welch's $t$-test) and those of multiple groups were analyzed by one-way ANOVA followed by Tukey's test. A $P$-value of $<0.05$ was considered significant.

\section{RESULTS}

\section{Cytotoxic and Antiviral Effects of 5-ALA}

Cytotoxicity assay was performed to clarify the non-toxic concentration of 5-ALA against fcwf-4 cells (Figure 1). More than $75 \%$ of fcwf- 4 cells survived in the presence of $1,000 \mu \mathrm{M} 5$ ALA (the maximum concentration in this experiment). Vehicle control exhibit no cytotoxic effects on fcwf- 4 cells.

\section{The Effects of 5-ALA on FIPV Infection in Feline Cell-Line}

The antiviral effects of 5-ALA against FIPV were evaluated by plaque inhibition assay in fcwf- 4 cells. Cells were treated with 5-ALA through the following 3 procedures: 24-h pretreatment (pre-24h), 24-h pre-treatment followed by $49-\mathrm{h}$ cotreatment with FIPV (pre-24h and co- $49 \mathrm{~h}$ ), and 48 -h pretreatment followed by $49-\mathrm{h}$ co-treatment with FIPV (pre- $48 \mathrm{~h}$ and co- $49 \mathrm{~h}$ ). In pre- $24 \mathrm{~h}$, the percentage of plaque inhibition significantly increased at $500 \mu \mathrm{M}$ or higher (Figures 2A,B). In pre- $24 \mathrm{~h}$ and co- $49 \mathrm{~h}$, the percentage of plaque inhibition significantly increased at $125 \mu \mathrm{M}$ or higher (Figures 2C,D). In pre- $48 \mathrm{~h}$ and co- $49 \mathrm{~h}$, the percentage of plaque inhibition in type I FIPV by $125 \mu \mathrm{M}$ 5-ALA reached $75 \%$ (Figures 2E,F). Vehicle control, SFC, exhibited no plaque-inhibitory effects on FCoV under any condition. According to the titration assay, the production of type I and type II FIPV was significantly reduced by 250 and $500 \mu \mathrm{M}$ 5-ALA (Figure 3).

\section{The Effects of 5-ALA on FIPV Infection in a Feline Cell Line}

FIPV-infected macrophages are involved in the progression of FIP symptoms to a severe state. We investigated whether 

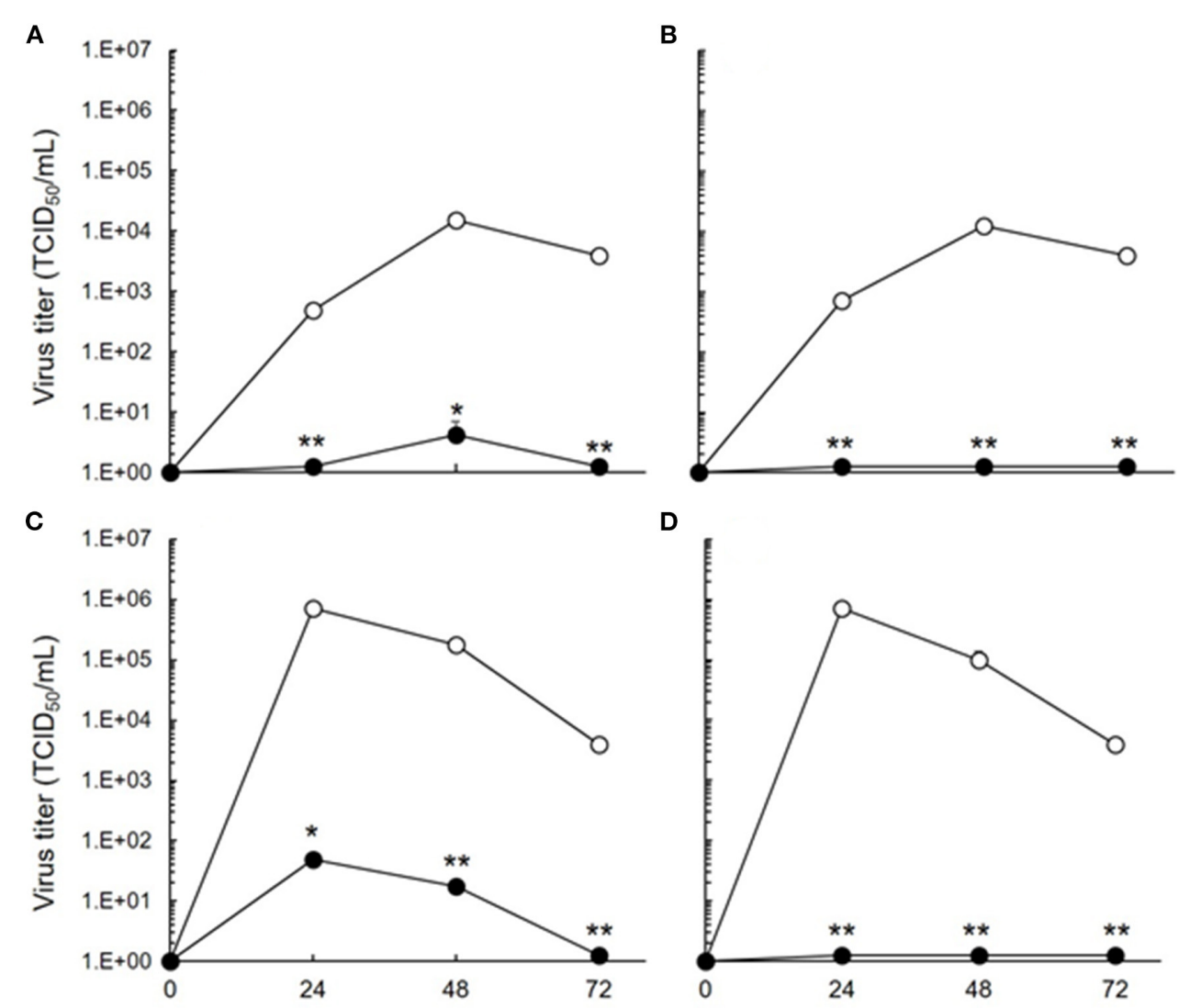

Hours of post inoculation of virus

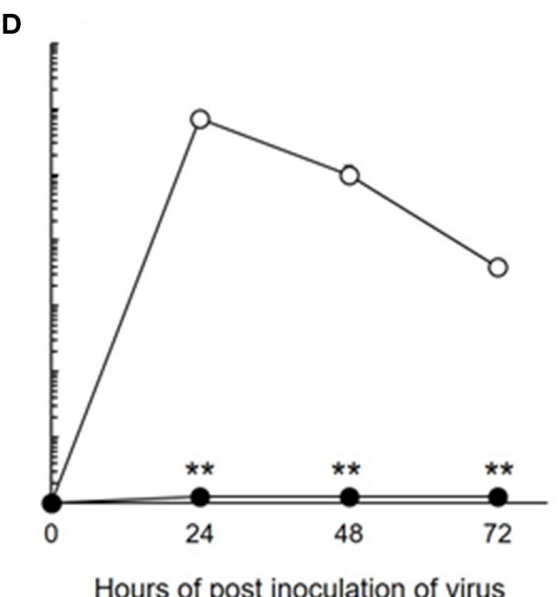

FIGURE 3 | Inhibition of FIPV infection by 5-ALA in fcwf-4 cells. (A,C) Effects of 48-h pre-treatment and 48-h post-treatment on antiviral activity of $250 \mu$ M 5-ALA. (B,D) Effects of 48-h pre-treatment and 48-h post-treatment on antiviral activity of $500 \mu \mathrm{M} 5$-ALA. (A,B) $250 \mu \mathrm{M}$ 5-ALA. (A,B) type I FIPV. (C,D) type II FIPV. Black circle: 5-ALA. White circle: Vehicle (solvent control). The results are shown as the mean \pm SE. Data represent four independent experiments $(n=4)$. ${ }^{* *} p<0.01\left({ }^{*} p<\right.$ $0.05)$ vs. vehicle.

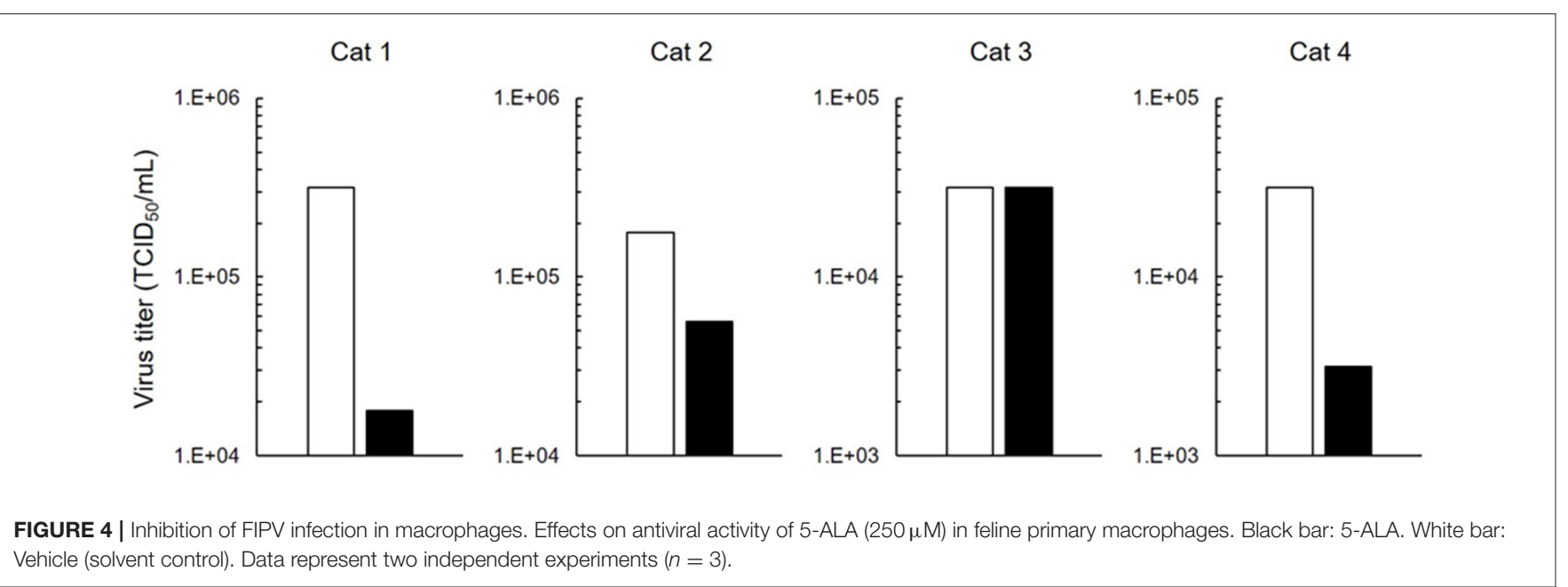

5-ALA inhibits FIPV multiplication in macrophages. In this experiment, type II FIPV 79-1146 with high ability of multiplication in feline primary macrophages was used. Virus production in FIPV-infected macrophages was reduced by $250 \mu \mathrm{M}$ 5-ALA in three of four cats (Figure 4). 


\section{DISCUSSION}

5-ALA is an intermediate of tetrapyrrole synthesis in animals, plants, and microorganisms (13-15). In the 1980's, the possibility of efficacy of 5-ALA in plants was reported (18), but it was difficult to produce 5-ALA in a sufficient amount for practical use because only a small amount is produced in microorganisms. After Nishikawa et al. established a mass production method of 5-ALA using bacteria (19), the effectiveness of 5-ALA was confirmed in not only agriculture, but also in medical and biological fields. 5-ALA is inexpensive, and it is practically used as a supplement to improve animal performance and immune response in the field of veterinary medicine $(14,20)$.

5-ALA inhibited the growth of FIPV in fcwf- 4 cells. Metal complexes of a 5-ALA metabolite, protoporphyrin IX (PpIX), have been reported to have anti-virus activity (21-23). A PpIX metal complex, heme, inhibits dengue virus multiplication (21). On the other hand, multiplication of Zika virus is not inhibited by heme (23). It is unclear whether heme inhibits FCoV multiplication. Generally, an increase in intracellular heme stimulates the production of hemeoxygenase-1 (HO$1)$, the heme-degrading enzyme. HO-1 has been reported to induce anti-viral activity $(24,25)$. However, we confirmed in a preliminary experiment that the HO-1 mRNA expression level was unchanged in cells treated with $250 \mu \mathrm{M}$ 5-ALA (Data not shown). Based on this, 5-ALA-induced inhibition of FIPV infection occurs due to a factor other than heme and $\mathrm{HO}-1$.

There have been many recent studies on therapeutic drugs for FIP. Many drugs effective for FIP in vitro were identified and several have been confirmed to exhibit treatment effects when administered to cats with FIP (10-12). However, the effects of all drugs were poor in cases with neurological manifestations. As a reason for this, poor transfer of these drugs to the central nervous system was considered; therefore, a drug exhibiting antiviral effects against FIPV able to reach brain tissue is needed. 5-ALA is a low-molecular-weight amino acid and can transfer to brain tissue (26). In addition, it has been reported that the diffusion of 5-ALA from blood to normal brain tissue is very low (27), suggesting that it exhibits fewer adverse effects. FIP can be definitely diagnosed only by detection of the FCoV antigen within lesion (28). However, when treatment is initiated after making a definite diagnosis, symptoms have progressed and the condition does not respond to treatment in many cases. Therefore, if a drug that can be prophylactically administered before diagnosing FIP is available, progression of symptoms may be prevented, for which 5-ALA may be ideal agent. However, in our experiment using the target cells of FIPV, macrophages, the antiviral effects of 5-ALA were not observed in some cats. Therefore, when 5-ALA is used as a therapeutic drug for FIP, antiFCoV drugs, such as GS-441524 (29), GC-376 (30), U18666A (31), and itraconazole (32), or anti-inflammatory drugs, such as anti-TNF-alpha antibody (33), should be concomitantly used.

In the field, FECV is mainly transmitted between cats, whereas horizontal infection of FIPV between cats is considered rare (34). FIPV was suggested to be generated by genetic mutation of FECV. Thus, if there are means to prevent FECV infection on a daily basis, the development of FIP may be prevented. No vaccine capable of preventing FECV infection has been developed. Addie et al. reported that virus gene excretion in feces disappeared in FECV-infected cats treated with a synthetic adenosine analog (35). Therefore, removal of FECV infecting the intestine by antiviral administration to FECV-infected cats is expected. However, synthetic adenosine analogs may induce coronavirus gene mutation (36). Moreover, even though the FECV gene level in feces decreased to below the detection limit in cats treated with a synthetic adenosine analog, it is possible for FECV to latently infect the intestine or other tissues. To prevent FECV gene mutation and reliably eradicate FECV infection, long-term synthetic adenosine analog administration is necessary, but it is not realistic because this drug is too expensive. On the other hand, 5-ALA is practically used as a supplement. 5ALA has low toxicity in animals and plants, strongly suggesting that long-term administration of 5-ALA to cats is possible. It is necessary to investigate whether 5-ALA is applicable as a supplement to prevent the development of FIP in FECV-infected cats in the future.

In this study, we confirmed the possibility that 5-ALA inhibits FIPV multiplication and TNF-alpha production. As 5-ALA is an amino acid present in the body, its immediate administration is possible. However, it is necessary to administer 5-ALA to cats with FIP and observe whether therapeutic effects can be acquired. Furthermore, whether long-term administration of 5ALA eliminates the virus and inhibits FIP development in FECVinfected cats must be investigated.

\section{DATA AVAILABILITY STATEMENT}

The original contributions presented in the study are included in the article/supplementary material, further inquiries can be directed to the corresponding author/s.

\section{ETHICS STATEMENT}

The animal study was reviewed and approved by the President of Kitasato University through judgment of the Institutional Animal Care and Use Committee of Kitasato University.

\section{AUTHOR CONTRIBUTIONS}

TT conceived and designed the study, analysed the data, and wrote the manuscript. TT and KS collected the data. TT, KS, and TD collected and processed the samples. All authors read and approved the final manuscript.

\section{FUNDING}

The authors declare that this study received funding from Neopharma Japan Co., Ltd. The funder was not involved in the study design, collection, analysis, interpretation of data, the writing of this article or the decision to submit it for publication. 


\section{REFERENCES}

1. ICTV. Coronaviridae. Virus Taxonomy: 2019 Release. (2020). Available online at: https://talk.ictvonline.org/ictv-reports/ictv_9th_report/positive-senserna-viruses-2011/w/posrna_viruses/222/coronaviridae (accessed December 25, 2020).

2. Motokawa K, Hohdatsu T, Aizawa C, Koyama H, Hashimoto H. Molecular cloning and sequence determination of the peplomer protein gene of feline infectious peritonitis virus type I. Arch Virol. (1995) 140:46980. doi: 10.1007/BF01718424

3. Hohdatsu T, Okada S, Ishizuka Y, Yamada H, Koyama H. The prevalence of types I and II feline coronavirus infections in cats. J Vet Med Sci. (1992) 54:557-62. doi: 10.1292/jvms.54.557

4. Kummrow M, Meli ML, Haessig M, Goenczi E, Poland A, Pedersen NC, et al. (2005). Feline coronavirus serotypes 1 and 2: seroprevalence and association with disease in Switzerland. Clin Diagn Lab Immunol. 12:120915. doi: 10.1128/CDLI.12.10.1209-1215.2005

5. Wang YT, Chueh LL, Wan CH. An 8-year epidemiologic study based on baculovirus-expressed type-specific spike proteins for the differentiation of type I and II feline coronavirus infections. BMC Vet Res. (2014) 10:186. doi: 10.1186/s12917-014-0186-7

6. Pedersen NC. An overview of feline enteric coronavirus and infectious peritonitis virus infections. Feline Pract. (1995) 23:7-21.

7. Chang HW, Egberink HF, Halpin R, Spiro DJ, Rottier PJ. Spike protein fusion peptide and feline coronavirus virulence. Emerg Infect Dis. (2012) 18:1089. doi: 10.3201/eid1807.120143

8. Licitra BN, Millet JK, Regan AD, Hamilton BS, Rinaldi VD, Duhamel GE, et al. Mutation in spike protein cleavage site and pathogenesis of feline coronavirus. Emerg Infect Dis. (2013) 19:1066. doi: 10.3201/eid1907.121094

9. Tekes G, Thiel HJ. Feline coronaviruses: pathogenesis of feline infectious peritonitis. Adv Virus Res. (2016) 96:193218. doi: 10.1016/bs.aivir.2016.08.002

10. Pedersen NC, Kim Y, Liu H, Galasiti Kankanamalage AC, Eckstrand C, Groutas WC, et al. Efficacy of a 3C-like protease inhibitor in treating various forms of acquired feline infectious peritonitis. J Feline Med Surg. (2018) 20:378-92. doi: 10.1177/1098612X17729626

11. Pedersen NC, Perron M, Bannasch M, Montgomery E, Murakami E, Liepnieks $\mathrm{M}$, et al. Efficacy and safety of the nucleoside analog GS441524 for treatment of cats with naturally occurring feline infectious peritonitis. J Feline Med Surg. (2019) 21:271-81. doi: 10.1177/1098612X198 25701

12. Kameshima S, Kimura Y, Doki T, Takano T, Park CH, Itoh N. Clinical efficacy of combination therapy of itraconazole and prednisolone for treating effusive feline infectious peritonitis. J Vet Med Sci. (2020) 82:14926. doi: 10.1292/jvms.20-0049

13. Czarnecki O, Grimm B. New insights in the topology of the biosynthesis of 5-aminolevulinic acid. Plant Signal Behav. (2013) 8:e23124. doi: 10.4161/psb.23124

14. Hendawy AO, Khattab MS, Sugimura S, Sato K. Effects of 5aminolevulinic acid as a supplement on animal performance, iron status, and immune response in farm animals: a review. Animals. (2020) 10:1352. doi: 10.3390/ani10081352

15. Sasaki K, Watanabe M, Tanaka T, Tanaka T. Biosynthesis, biotechnological production and applications of 5-aminolevulinic acid. Appl Microbiol Biotechnol. (2002) 58:23-9. doi: 10.1007/s00253-001-0858-7

16. Suzuki S, Hikosaka K, Balogun EO, Komatsuya K, Niikura M, Kobayashi $\mathrm{F}$, et al. In vivo curative and protective potential of orally administered 5-aminolevulinic acid plus ferrous ion against malaria. Antimicrob Agents Chemother. (2015) 59:6960-7. doi: 10.1128/AAC.01910-15

17. Osaki T, Yokoe I, Ogura S, Takahashi K, Murakami K, Inoue K, et al. Photodynamic detection of canine mammary gland tumors after oral administration of 5-aminolevulinic acid. Vet Comp Oncol. (2017) 15:7319. doi: $10.1111 /$ vco. 12213

18. Rebeiz CA, Montazer-Zouhoor A, Hopen HJ, Wu SM. Photodynamic herbicides: 1. Concept and phenomenology. Enzyme Microb Technol. (1984) 6:390-401. doi: 10.1016/0141-0229(84)90012-7

19. Nishikawa S, Watanabe K, Tanaka T, Miyachi N, Hotta Y, Murooka Y. Rhodobacter sphaeroides mutants which accumulate 5-aminolevulinic acid under aerobic and dark conditions. J Biosci Bioeng. (1999) 87:798804. doi: 10.1016/S1389-1723(99)80156-X
20. Sasaki A, Iwatani N, Harada K. Improvement effect of 5-aminolevulinic acid on hyperlipidemia in miniature schnauzer dogs: an open study in 5 cases of one pedigree. Yonago Acta Med. (2020) 63:234-8. doi: 10.33160/yam.2020.08.006

21. Assunção-Miranda I, Cruz-Oliveira C, Neris RLS, Figueiredo CM, Pereira LPS, Rodrigues D, et al. Inactivation of dengue and yellow fever viruses by heme, cobalt-protoporphyrin IX and tin-protoporphyrin IX. J Appl Microbiol. (2016) 120:790-804. doi: 10.1111/jam.13038

22. Cruz-Oliveira C, Almeida AF, Freire JM, Caruso MB, Morando MA, Ferreira VN, et al. Mechanisms of vesicular stomatitis virus inactivation by protoporphyrin IX, zinc-protoporphyrin IX, and mesoporphyrin IX. Antimicrob Agents Chemother. (2017) 61:e00053-17. doi: 10.1128/AAC.00053-17

23. Neris RL, Figueiredo CM, Higa LM, Araujo DF, Carvalho CA, Verçoza $\mathrm{BR}$, et al. Co-protoporphyrin IX and Sn-protoporphyrin IX inactivate Zika, Chikungunya and other arboviruses by targeting the viral envelope. Sci Rep. (2018) 8:9805. doi: 10.1038/s41598-018-27855-7

24. Espinoza JA, González PA, Kalergis AM. Modulation of antiviral immunity by heme oxygenase-1. Am J Pathol. (2017) 187:48793. doi: 10.1016/j.ajpath.2016.11.011

25. Tseng CK, Lin CK, Wu YH, Chen YH, Chen WC, Young KC, et al. Human heme oxygenase 1 is a potential host cell factor against dengue virus replication. Sci Rep. (2016) 6:32176. doi: 10.1038/srep32176

26. Novotny A, Xiang J, Stummer W, Teuscher NS, Smith DE, Keep RF. Mechanisms of 5 -aminolevulinic acid uptake at the choroid plexus. $J$ Neurochem. (2000) 75:321-8. doi: 10.1046/j.1471-4159.2000.0750321.x

27. Ennis SR, Novotny A, Xiang J, Shakui P, Masada T, Stummer W, et al. Transport of 5-aminolevulinic acid between blood and brain. Brain Res. (2003) 959:226-34. doi: 10.1016/S0006-8993(02)03749-6

28. Tasker S. Diagnosis of feline infectious peritonitis: update on evidence supporting available tests. J Feline Med Surg. (2018) 20:228-43. doi: 10.1177/1098612X18758592

29. Murphy BG, Perron M, Murakami E, Bauer K, Park Y, Eckstrand C, et al. The nucleoside analog GS-441524 strongly inhibits feline infectious peritonitis (FIP) virus in tissue culture and experimental cat infection studies. Vet Microbiol. (2018) 219:226-33. doi: 10.1016/j.vetmic.2018.04.026

30. Kim Y, Liu H, Galasiti Kankanamalage AC, Weerasekara S, Hua DH, Groutas WC, et al. Reversal of the progression of fatal coronavirus infection in cats by a broad-spectrum coronavirus protease inhibitor. PLoS Pathog. (2016) 12:e1005531. doi: 10.1371/journal.ppat.1005531

31. Takano T, Endoh M, Fukatsu H, Sakurada H, Doki T, Hohdatsu T. The cholesterol transport inhibitor U18666A inhibits type I feline coronavirus infection. Antiviral Res. (2017) 145:96102. doi: 10.1016/j.antiviral.2017.07.022

32. Takano T, Akiyama M, Doki T, Hohdatsu T. Antiviral activity of itraconazole against type I feline coronavirus infection. Vet Res. (2019) 50:5. doi: 10.1186/s13567-019-0625-3

33. Doki T, Takano T, Kawagoe K, Kito A, Hohdatsu T. Therapeutic effect of antifeline TNF-alpha monoclonal antibody for feline infectious peritonitis. Res Vet Sci. (2016) 104:17-23. doi: 10.1016/j.rvsc.2015.11.005

34. Pedersen NC. An update on feline infectious peritonitis: virology and immunopathogenesis. Vet J. (2014) 201:12332. doi: 10.1016/j.tvjl.2014.04.017

35. Addie DD, Curran S, Bellini F, Crowe B, Sheehan E, Ukrainchuk L, et al. Oral Mutian ${ }^{\circledR}$ X stopped faecal feline coronavirus shedding by naturally infected cats. Res Vet Sci. (2020) 130:222-9. doi: 10.1016/j.rvsc.2020.02.012

36. Pruijssers AJ, Denison MR. Nucleoside analogues for the treatment of coronavirus infections. Curr Opin Virol. (2019) 35:57-62. doi: 10.1016/j.coviro.2019.04.002

Conflict of Interest: The authors declare that the research was conducted in the absence of any commercial or financial relationships that could be construed as a potential conflict of interest.

Copyright (c) 2021 Takano, Satoh and Doki. This is an open-access article distributed under the terms of the Creative Commons Attribution License (CC BY). The use, distribution or reproduction in other forums is permitted, provided the original author(s) and the copyright owner(s) are credited and that the original publication in this journal is cited, in accordance with accepted academic practice. No use, distribution or reproduction is permitted which does not comply with these terms. 